\title{
A study on heavy metals contamination of surfacial materials by environmental magnetism and chemical analysis in Antaibao Open Pit Coal Mine, Shanxi Province, China
}

\author{
Manrong Chen ${ }^{1 . *}$, Shangyi Wang ${ }^{2}$, Binbin $\mathrm{Yu}^{1}$, Weiguo Zhang ${ }^{3}$, and Lizhong $\mathrm{Yu}^{3}$ \\ ${ }^{1}$ Environmental Science and Engineering College, Yangzhou University, Jiangsu province, Yangzhou, 225127, China. \\ ${ }^{2}$ Research Center for Scientific Development in Fenhe River Valley, Taiyuan Normal University, Taiyuan, Shanxi, 030012, China. \\ ${ }^{3}$ State Key Lab. of Estuarine and Coastal Research, East China Normal University (ECNU), Shanghai, 200062,China.
}

\begin{abstract}
Antaibao Open Pit Coal Mine(AOPCM)'s mining activities have caused heavy metals contamination of surface, so it was urgent task to find a suitable method and survey full and prompt and long-term monitor on the heavy metals pollution. We chose methods of environmental magnetism and chemical analysis to analyze the surface materials on heavy metals contamination, by correlation of magnetic parameters and contents of chemical analysis, we can greatly reduce workload of chemical analysis and then achieve greater, faster, better, non-destructive, less chemical pollution and more economical results. The magnetic parameters and its groups act as proxy for the contents from chemical analysis. Three different sample areas sediments: loess or loess-like sediments, sedimentary rocks and alluvium, samples have different values of magnetic parameters. The values of magnetic susceptibility in this study were lower than others sediments and soils, secondly, the base rock and sedimentary rocks from the FD were of lower values of magnetic susceptibility than others of AOPCM. Contamination of $\mathrm{Pb}$ and $\mathrm{Cd}$ are more serious than other heavy metals. we can infer the contaminated level of anthropogenic heavy metals, DS $>$ OD $>$ FD. The mechanism may be mainly by the origin of the magnetic fraction in the anthropogenic particulate pollution and connected with the high-temperature technological processes during production and/or processing materials which have significant Fe content. Another point, when we want to study mechanism of magnetic properties used as proxy of heavy metals, the weak magnetic samples were measured and analyzed, we should be carefully.
\end{abstract}

\section{Introduction}

Heavy metals pollution in open pit coal mine attracted the attention of academic researchers for long periods around the world.

The Antaibao Open Pit Coal Mine (AOPCM) (see Fig. 1)cooperated with Western Petroleum Company, USA, till 1991, is one of the largest open pit coal mines in the world, total area about $376 \mathrm{~km}^{2}$, constructed in 1985, and coal production in September 1987, raw coal production $15.33 \mathrm{Mt} / \mathrm{a}$ (Hao zhi, 1999). This mine service period is 1985-2077, the stripping-to-ore-ratio was about $5.5 \mathrm{~m}^{3} / \mathrm{t}$ (Hong Yu, 1995), roughly total about 2,107,875,000 $\mathrm{m}^{3}$ overburden materials were produced to September 2012 from then, parts of tremendous overburden materials piled on the surface with elements from deep underground, included emissions of heavy metals from fossil fuel combustion, and atmospheric particulates fallout, and life wastes etc., heavy metals concentration of the surface materials may be changed in the mining areas. Scientists from Beijing Normal University completed research on heavy metals pollution of AOPCM (Wang S. et al., 1987). For purpose of cleaning coal, some authors studied the elements (heavy metals, major elements and rare earth elements) in coal of AOPCM, but all-round monitoring and investigation reports on the heavy metals contamination of surface materials have not been read by authors.

Environmental magnetism (R. Thompson \& F. Oldfield, 1986) was applied to study heavy metals contamination in soils, dusts, peats and sediments from 1980's. The magnetic parameters were used as proxies to monitoring the concentration of heavy metals, by correlation between magnetic parameters, and the concentrations of $\mathrm{Cu}, \mathrm{Pb}, \mathrm{Zn}, \mathrm{Cd}, \mathrm{Cr}, \mathrm{Hg}$, etc., which be analyzed by ICP-AES (atomic emission spectroscopy with inductively coupled plasma), and AAS (Atomic Absorption Spectrophotometer) and samples pretreatment by $\mathrm{HNO}_{3}-\mathrm{HF}-\mathrm{HClO}_{4}$ decomposition method. Which opened up the possibility that magnetic measurement might have a role to play in pollution monitoring.

\section{Material and methods}

Corresponding author: mrchen@yzu.edu.cn 


\subsection{Sampling strategy}

To understand the state of heavy metals contamination in the AOPCM, sampling strategy not only focus on mine area, but also the downstream of the river system. (DS , OD and FD,3 sampling areas)

\subsection{Chemical analysis on Sediments and soils}

The samples were dried in oven at $40^{\circ} \mathrm{C}$, for metal analysis, and be dissolved by concentrated $\mathrm{HCl}-\mathrm{HF}-\mathrm{HClO}_{4}$ acid attack. The total contents of $\mathrm{Cd}$, $\mathrm{Cu}, \mathrm{Pb}, \mathrm{Fe}, \mathrm{As}, \mathrm{Cr}, \mathrm{Hg}$ were analyzed in 44 samples.

\subsection{Environmental magnetic measurement}

All the magnetic measurements were carried out in the State Key Laboratory of Estuarine and Coastal Research at East China Normal University. The instruments include Bartington MS2 magnetic susceptibility meter, Molspin demagnetizer, pulse magnetizer and Minispin magnetometer.

\section{Results and discuss}

\subsection{The characteristics of magnetic properties} and heavy metal concentration of sediments in AOPCM

3.1.1 The characteristics of magnetic properties of surfacial sediments in AOPCM

3.1.1.1 The general magnetic characteristics of surfaciel materials in AOPCM

The magnetic properties of surface materials in AOPCM showed in the Table 1 to Table 3 .we can roughly understand the magnetic characteristics of the surface materials.

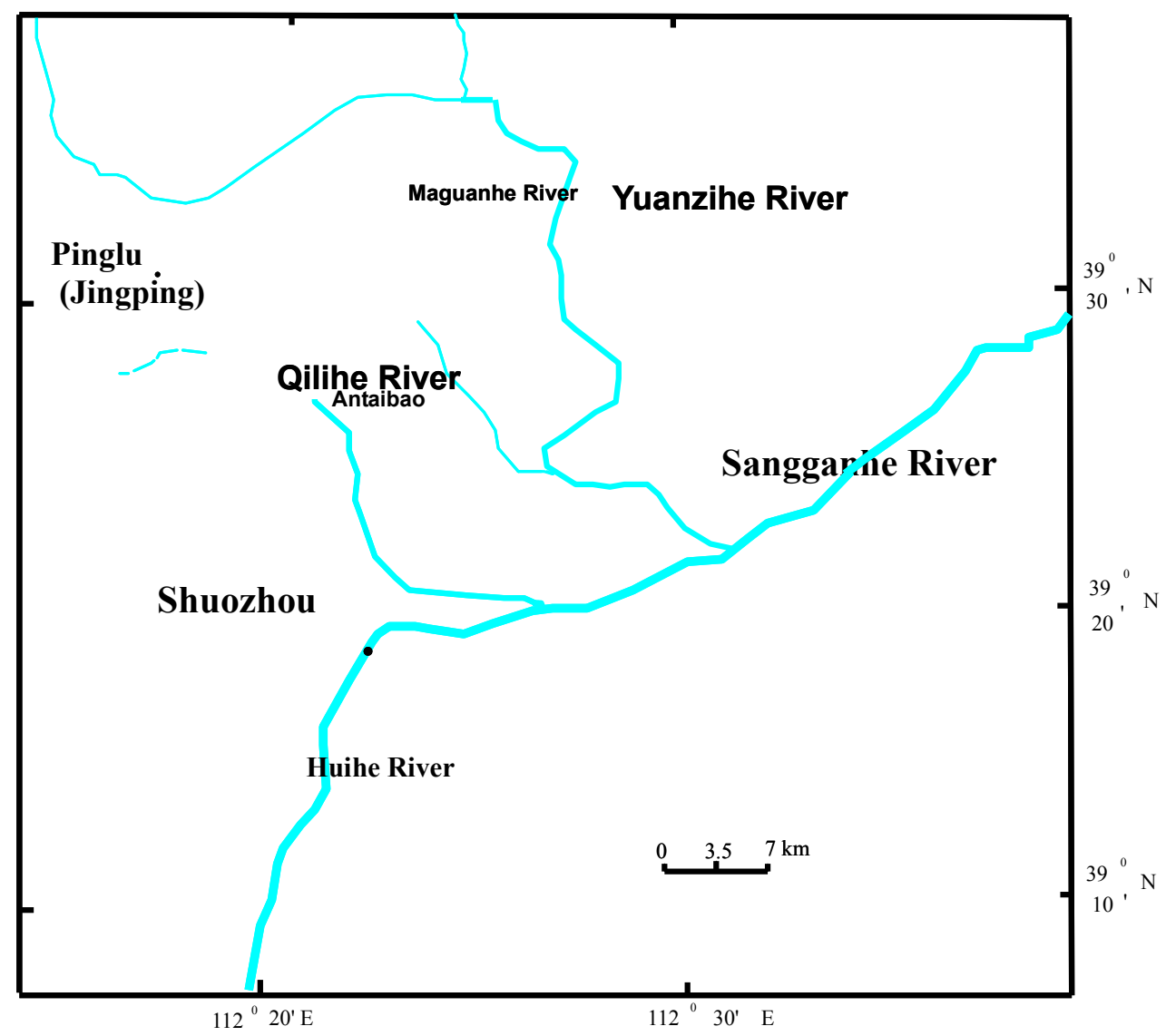

Fig. 1 The location of Antaibao Open Pit Coal Mine ( AOPCM)

Table 1 Statistics of magnetic parameters of sediments in AOPCM $(n=40)$

\begin{tabular}{|c|c|c|c|c|c|c|}
\hline parameters & Mean & Range & Standard Dev. parameters & Mean & Range & Standard Dev. \\
\hline $\begin{array}{l}\chi\left(10^{8} \mathrm{~m}^{3} / \mathrm{kg}\right) \\
\text { SIRM }\left(10^{-6} \mathrm{Am}\right.\end{array}$ & $\begin{array}{l}41.28 \\
6555.3\end{array}$ & $\begin{array}{c}0.66-118.37 \\
55.66-50266.03\end{array}$ & $\begin{array}{l}\chi_{\mathrm{fd}}\left(10^{8} \mathrm{~m}^{3} / \mathrm{kg}\right. \\
\text { ARM }\left(10^{-6} \mathrm{Am}^{2}\right)\end{array}$ & $\begin{array}{c}3.43 \\
\text { g) } 109.85\end{array}$ & $\begin{array}{r}-11.29-33.43 \\
1.95-290.61\end{array}$ & $\begin{array}{l}7.07 \\
68.43\end{array}$ \\
\hline
\end{tabular}




\begin{tabular}{|c|c|c|c|c|c|c|}
\hline$\chi_{\text {arm }}\left(10^{-8} \mathrm{~m}^{3} / \mathrm{kg}\right)$ & 150.16 & $6.13-512.3$ & 102.91 & $\operatorname{HIRM}\left(10^{-6} \mathrm{Am}^{2} / \mathrm{kg}\right) 435.62$ & $-732.19-2900.45$ & 707.52 \\
\hline $\operatorname{IRM}_{-100}\left(10^{-6} \mathrm{Am}^{2} / 1\right.$ & kg) -2436 & $.46-8611.50-2639.21$ & 2157.49 & $\operatorname{IRM}_{-300}\left(10^{-6} \mathrm{Am}^{2} / \mathrm{kg}\right)-5734.11$ & $-51390.08 \sim-25.50$ & 8575.00 \\
\hline $\mathrm{S}_{-100}$ & 70.82 & $21.63-87.99$ & 13.56 & $\mathrm{~S}_{-300}$ & $52.24-104.54$ & 13.21 \\
\hline$\chi_{\mathrm{arm}} / \chi$ & 6.10 & $0.88-99.12$ & 15.19 & $\chi_{\mathrm{arm} /} \operatorname{SIRM}\left(10^{-2} \mathrm{~m} / \mathrm{A}\right) 58.48$ & $3.17-1079.30$ & 167.12 \\
\hline L-ratio & 0.38 & $-0.20-2.91$ & 0.54 & $(\mathrm{kA} / \mathrm{m}) 16.18$ & $1.27-100.89$ & 16.62 \\
\hline SIRM/ARM & 65.78 & $2.91-396.64$ & 68.72 & & & \\
\hline
\end{tabular}

Comparing the lower arithmetic mean value in this study, so samples may be dominated by magnetic mineral haematite, and low $\chi$ in this study may be affected by much calcite in sample. see Table 2 .

The $\chi$ vs. SIRM showed that weak positive correlation and lower values, the concentration of ferrimgnetic mineral may be lower, and the $\chi_{\text {ARM }}$ vs. $\chi$ for magnetic granulometry, samples with higher values of $\chi_{\text {ARM }}$ have SD and PSD grain of magnetite, from J. King et al. (1982), a new method for identifying relative grain size variations in magnetite involves the parameter anhysteretic (ARM) or anhysteretic susceptibility $\left(\chi_{\text {ARM }}\right)$, which is particularly sensitive to the single domain (SD) and small pseudo-single domain (SPD) grains of the finer magnetite fraction, similarly the $\chi$ is sensitive to larger PSD and smaller multidomain (MD) .

\subsubsection{The different of magnetic characteristics in three sampling areas}

As the three different areas sediments: loess or loess-like sediments, sedimentary rocks and alluvium, samples have different values of magnetic parameters. (see Table 2)

Table 2 Statistics of main magnetic parameters in different sampling area in AOPCM

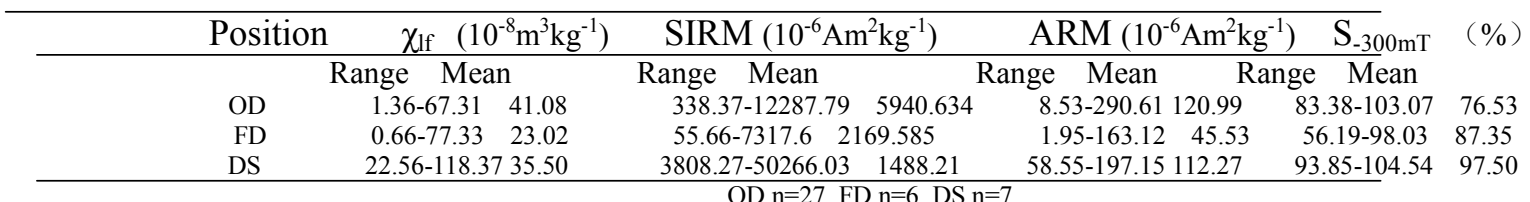

\subsubsection{Low values of magnetic susceptibility of sedimentary rock in AOPCM}

We compared sedimentary rocks samples in this study with relative researches, which showed that conclusions: the firstly, the values of magnetic susceptibility in this study were lower than others sediments and soils, secondly, the base rock and sedimentary rocks from the FD were of lower values of magnetic susceptibility than others of AOPCM.

According to the researches by many authors, sedimentary rocks are of low magnetic susceptibility, because the magnetic minerals were dissolution.

\subsubsection{The heavy metal concentration of surfacial sediments in AOPCM}

\subsubsection{The general characteristics of heavy metals concentration in sediments in AOPCM}

According to the Table 3 , the concentrations of $\mathrm{Cu}$, $\mathrm{Pb}, \mathrm{Cr}, \mathrm{Hg}, \mathrm{Cd}, \mathrm{As}, \mathrm{Fe}$ are different greatly in 44 samples, the range of values of $\mathrm{Cu}, \mathrm{Pb}, \mathrm{Cr}, \mathrm{Hg}, \mathrm{Cd}, \mathrm{As}$, $\mathrm{Fe}$ and $\mathrm{Al}$ are showed in statistic, the ratios $($ maximum $/$ minimum) are $7.65(\mathrm{Cd})>4.07(\mathrm{Hg})>3$ $(\mathrm{Fe})>\mathrm{Cr}(2.54)>\mathrm{Cu}(2.38)>2.07(\mathrm{~Pb})>1.88(\mathrm{As})$ respectively. The order of standard dev. are $\mathrm{Hg}>\mathrm{Cd}>$ $\mathrm{Fe}>\mathrm{As}>\mathrm{Cr}>\mathrm{Pb}>\mathrm{Cu}>\mathrm{Al}$. Antaibao open pit coal mine make geomorphological changes, and similarly to the heavy metals concentration of surface sediments. (see Table 3 and Table 4).

Table 3 The concentration ( $\mathrm{mg} / \mathrm{kg}$, but $\%$ for $\mathrm{Fe}$ and $\mathrm{Al})$ and $\mathrm{EF}$ of heavy metals of sediments in AOPCM

\begin{tabular}{|c|c|c|c|c|c|c|c|c|}
\hline Sample & $\mathrm{Cu}$ & $\mathrm{Pb}$ & $\mathrm{Cr}$ & $\mathrm{Hg}$ & $\mathrm{Cd}$ & $\mathrm{As}$ & $\mathrm{Fe}$ & $\mathrm{Al}$ \\
\hline PS01 & $20.24(1.03)$ & $31.22(1.34)$ & $80.2(1.33)$ & $0.039(0.99)$ & $0.073(1.00)$ & $9.57(0.99)$ & $1.92(0.80)$ & 6.53 \\
& & & & & & & & \\
\hline PS02 & $15.33(0.91)$ & $34.55(1.75)$ & $45.1(0.88)$ & $0.028(0.84)$ & $0.092(1.48)$ & $8.34(1.02)$ & $1.17(0.57)$ & 5.55 \\
\hline PS03 & $13.99(0.88)$ & $30.97(1.65)$ & $50.3(1.04)$ & $0.018(0.57)$ & $0.023(0.39)$ & $8.16(1.05)$ & $1.09(0.56)$ & 5.25 \\
\hline & & & & & & & & \\
\hline PS04 & $29.68(1.63)$ & $30.89(1.44)$ & $81.9(1.48)$ & $0.039(1.07)$ & $0.085(1.26)$ & $10.05(1.13)$ & $2.48(1.12)$ & 6.02 \\
& & & & & & & & \\
\hline PS05 & $28.55(1.35)$ & $30.68(1.23)$ & $70.2(1.09)$ & $0.038(0.90)$ & $0.098(1.25)$ & $8.86(0.86)$ & $2.28(0.88)$ & 6.99 \\
\hline PS06 & $25.48(1.28)$ & $38.99(1.66)$ & $59.7(0.98)$ & $0.018(0.45)$ & $0.089(1.21)$ & $9.97(1.02)$ & $2.19(0.90)$ & 6.59 \\
\hline PS07 & $26.26(1.45)$ & $37.69(1.76)$ & $68.9(1.24)$ & $0.028(0.77)$ & $0.067(1.00)$ & $8.34(0.94)$ & $2.26(1.02)$ & 6.01 \\
\hline PS08 & $20.36(1.06)$ & $30.62(1.35)$ & $87.6(1.50)$ & $0.017(0.44)$ & $0.058(0.82)$ & $8.12(0.86)$ & $2.64(1.13)$ & 6.35 \\
\hline PS09 & $24.99(1.41)$ & $35.68(1.71)$ & $80.3(1.48)$ & $0.034(0.96)$ & $0.088(1.34)$ & $8.66(1.00)$ & $2.34(1.08)$ & 5.87 \\
\hline PS10 & $28.25(1.34)$ & $37.83(1.52)$ & $90.1(1.40)$ & $0.028(0.67)$ & $0.176(2.26)$ & $9.38(0.91)$ & $2.49(0.97)$ & 6.96 \\
\hline PS11 & $26.12(1.31)$ & $35.35(1.50)$ & $75.8(1.25)$ & $0.041(1.03)$ & $0.167(2.27)$ & $8.22(0.84)$ & $2.64(1.09)$ & 6.59 \\
\hline PS12 & $24.02(1.25)$ & $37.69(1.66)$ & $64.2(1.10)$ & $0.038(0.99)$ & $0.077(1.08)$ & $8.85(0.94)$ & $2.12(0.91)$ & 6.35 \\
\hline PS13 & $22.69(1.21)$ & $30.11(1.36)$ & $90.1(1.57)$ & $0.038(1.02)$ & $0.077(1.11)$ & $9.72(1.06)$ & $2.57(1.13)$ & 6.19 \\
\hline
\end{tabular}




\begin{tabular}{|c|c|c|c|c|c|c|c|c|}
\hline PS14 & $29.02(1.63)$ & $31.97(1.52)$ & $80.2(1.47)$ & $0.028(0.78)$ & $0.099(1.50)$ & $8.84(1.01)$ & $2.07(0.95)$ & 5.91 \\
\hline PS15 & $20.69(1.11)$ & $22.34(1.01)$ & $74.1(1.30)$ & $0.025(0.67)$ & $0.062(0.90)$ & $8.68(0.95)$ & $1.56(0.68)$ & 6.18 \\
\hline PS16 & $15.68(0.83)$ & $45.65(2.05)$ & $90.2(1.57)$ & $0.036(0.95)$ & $0.058(0.83)$ & $8.67(0.94)$ & $2.57(1.12)$ & 6.25 \\
\hline PS17 & $12.69(0.69)$ & $22.58(1.03)$ & $60.4(1.07)$ & $0.029(0.78)$ & $0.057(0.83)$ & $8.43(0.93)$ & $1.37(0.61)$ & 6.12 \\
\hline PS18 & $24.65(1.08)$ & $23.68(0.88)$ & $68.4(0.98)$ & $0.038(0.83)$ & $0.088(1.04)$ & $9.12(0.81)$ & $3.11(1.11)$ & 7.58 \\
\hline PS19 & $20.68(0.99)$ & $23.69(0.96)$ & $56.2(0.88)$ & $0.037(0.88)$ & $0.058(0.75)$ & $7.33(0.71)$ & $2.06(0.81)$ & 6.94 \\
\hline PS20 & $16.39(0.86)$ & $46.23(2.05)$ & $66.2(1.13)$ & $0.037(0.97)$ & $0.054(0.76)$ & $8.76(0.94)$ & $2.35(1.01)$ & 6.33 \\
\hline PS21 & $28.36(1.53)$ & $34.36(1.57)$ & $57.4(1.02)$ & $0.038(1.03)$ & $0.084(1.23)$ & $8.57(0.95)$ & $2.38(1.06)$ & 6.12 \\
\hline HH22 & $25.25(1.35)$ & $30.02(1.36)$ & $50.3(0.88)$ & $0.025(0.67)$ & $0.067(0.97)$ & $6.65(0.73)$ & $2.19(0.96)$ & 6.18 \\
\hline $\mathrm{HH} 23$ & $28.62(1.26)$ & $30.41(1.13)$ & $56.9(0.82)$ & $0.024(0.53)$ & $0.147(1.75)$ & $6.38(0.57)$ & $3.01(1.09)$ & 7.52 \\
\hline HH24 & $26.45(1.42)$ & $30.36(1.38)$ & $75.6(1.33)$ & $0.031(0.83)$ & $0.169(2.45)$ & $9.08(0.99)$ & $\begin{array}{l}2.05(0.90) \\
\end{array}$ & 6.17 \\
\hline YZ25 & $24.05(1.25)$ & $36.01(1.59)$ & $82.3(1.41)$ & $0.037(0.96)$ & $0.064(0.90)$ & $10.05(1.07)$ & $2.03(0.87)$ & 6.35 \\
\hline YZ26 & $24.35(1.21)$ & $38.32(1.61)$ & $114.6(1.86)$ & $0.061(1.51)$ & $0.088(1.18)$ & $12.01(1.22)$ & $3.27(1.33)$ & 6.68 \\
\hline YM27 & $20.15(1.24)$ & $30.36(1.58)$ & $86.3(1.74)$ & $0.015(0.46)$ & $0.078(1.29)$ & $8.76(1.10)$ & $1.98(1.00)$ & 5.39 \\
\hline YM28 & $25.36(1.41)$ & $29.66(1.39)$ & $74.2(1.35)$ & $0.024(0.67)$ & $0.083(1.24)$ & $10.34(1.17)$ & $2.56(1.16)$ & 5.97 \\
\hline PS29 & $30.24(1.53)$ & $36.66(1.57)$ & $68.5(1.14)$ & $0.027(0.68)$ & $0.081(1.11)$ & $9.16(0.95)$ & $2.33(0.97)$ & 6.54 \\
\hline PS30 & $25.36(1.20)$ & $34.33(1.38)$ & $56.9(0.88)$ & $0.031(0.74)$ & $0.088(1.13)$ & $7.81(0.76)$ & $2.08(0.81)$ & 6.98 \\
\hline PS31 & $28.69(1.56)$ & $35.37(1.63)$ & $64.2(1.15)$ & $0.028(0.76)$ & $0.064(0.94)$ & $8.64(0.96)$ & $2.45(1.10)$ & 6.07 \\
\hline PS32 & $22.63(1.18)$ & $31.02(1.37)$ & $51.2(0.88)$ & $0.037(0.96)$ & $0.042(0.59)$ & $\begin{array}{l}8.28(0.88) \\
\end{array}$ & $\begin{array}{l}2.19(0.94) \\
\end{array}$ & 6.35 \\
\hline PS33 & $26.69(1.37)$ & $28.47(1.23)$ & $67.6(1.13)$ & $0.024(0.61)$ & $0.068(0.94)$ & $8.68(0.91)$ & $1.35(0.57)$ & 6.47 \\
\hline PS34 & $14.32(0.80)$ & $30.54(1.44)$ & $47.6(0.87)$ & $0.027(0.75)$ & $0.102(1.54)$ & $8.48(0.97)$ & $\begin{array}{l}1.46(0.67) \\
\end{array}$ & 5.93 \\
\hline PS35 & $26.58(1.26)$ & $30.58(1.23)$ & $84.2(1.31)$ & $0.038(0.90)$ & $0.083(1.07)$ & $10.26(1.00)$ & $2.25(0.88)$ & 6.97 \\
\hline PS36 & $26.22(1.39)$ & $24.36(1.09)$ & $49.5(0.86)$ & $0.041(1.09)$ & $0.167(2.39)$ & $9.43(1.02)$ & $2.14(0.93)$ & 6.25 \\
\hline PS37 & $25.87(1.42)$ & $27.02(1.26)$ & $58.2(1.05)$ & $0.017(0.47)$ & $0.076(1.13)$ & $8.71(0.98)$ & $2.07(0.93)$ & 6.02 \\
\hline $\begin{array}{ll}\text { PS38 } \\
\end{array}$ & $28.85(1.69)$ & $35.65(1.77)$ & $82.5(1.59)$ & $0.043(1.26)$ & $0.068(1.08)$ & $8.75(1.05)$ & $2.08(1.00)$ & 5.64 \\
\hline PS39 & $29.56(1.58)$ & $34.67(1.57)$ & $98.6(1.73)$ & $0.025(0.67)$ & $0.079(1.14)$ & $9.18(1.00)$ & $2.41(1.06)$ & 6.18 \\
\hline PS40 & $29.69(1.49)$ & $31.08(1.32)$ & $80.2(1.32)$ & $0.047(1.18)$ & $0.087(1.18)$ & $10.09(1.04)$ & $2.56(1.06)$ & 6.58 \\
\hline PS41 & $25.56(1.38)$ & $29.37(1.34)$ & $64.1(1.14)$ & $0.035(0.95)$ & $0.078(1.14)$ & $\begin{array}{l}8.64(0.95) \\
\end{array}$ & $\begin{array}{l}2.09(0.93) \\
\end{array}$ & 6.12 \\
\hline PS42 & $12.89(0.69)$ & $25.65(1.17)$ & $70.2(1.23)$ & $0.027(0.72)$ & $0.025(0.36)$ & $7.95(0.87)$ & $2.17(0.95)$ & 6.17 \\
\hline PS43 & $22.97(1.22)$ & $28.67(1.30)$ & $87.5(1.53)$ & $0.026(0.69)$ & $0.078(1.12)$ & $8.64(0.94)$ & $2.34(1.02)$ & 6.21 \\
\hline PS44 & $16.39(0.77)$ & $30.34(1.20)$ & $61.2(0.94)$ & $0.044(1.03)$ & $0.029(0.37)$ & $8.69(0.83)$ & $1.98(0.76)$ & 7.08 \\
\hline Mean EFs & 1.24 & 1.43 & 1.23 & 0.83 & 1.17 & 0.95 & 0.94 & \\
\hline
\end{tabular}

Note: Data in the parentheses are enrichment factor $(\mathrm{EF})$.

Table 4 Statistics of the heavy metals and EFs in the AOPCM $(\mathrm{n}=44)(\mathrm{mg} / \mathrm{kg}$, but $\%$ for $\mathrm{Fe}$ and $\mathrm{Al})$

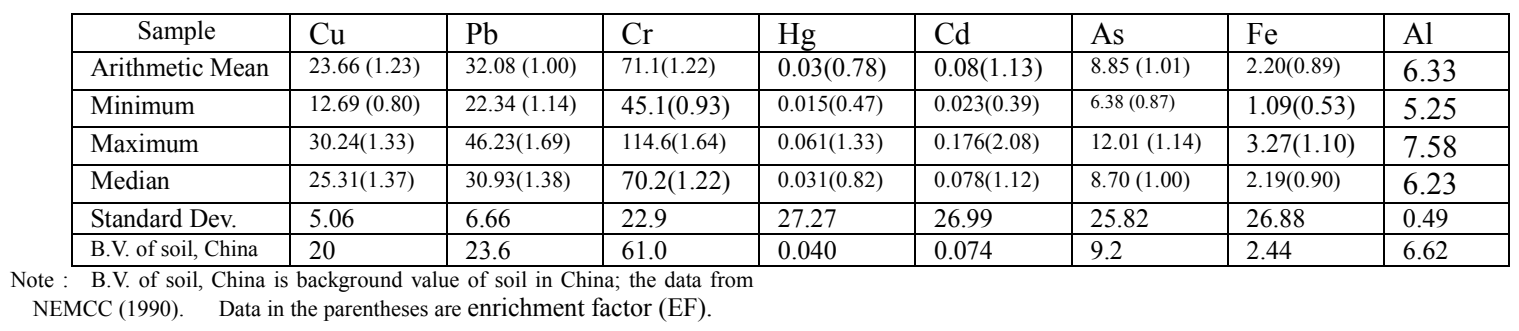

\subsubsection{Enrichment Factors (EFs) of heavy metals in AOPCM}

In order to identify the anthropogenic source of metallic elements, enrichment factor (EF) is widely employed. The formula was:

$$
\mathrm{EF}=(\mathrm{Me} / \mathrm{Al})_{\text {sample }} /(\mathrm{Me} / \mathrm{Al})_{\text {soil }}
$$

Where $(\mathrm{Me} / \mathrm{Al})$ sample is the metal to $\mathrm{Al}$ ratio in the samples; $(\mathrm{Me} / \mathrm{Al})_{\text {soil }}$ is the average ratio in soils in China (NEMCC, 1990). Based on Wang et al., (2012), $\mathrm{EF}$ values between $0.5-1.5$ (i.e. $0.5 \leqslant \mathrm{EF} \geqslant 1.5$ ) suggest that trace metals may be entirely from natural weathering processes and greater than 1.5 (i.e. $\mathrm{EF}>1.5$ ) suggest that a significant portion of trace metal is delivered from non-natural weathering processes. The mean values of EFs in this study are $\mathrm{Pb}>\mathrm{Cu}>\mathrm{Cr}>$ $\mathrm{Cd}>\mathrm{As}>\mathrm{Fe}>\mathrm{Hg}$. The enrichment factors of $\mathrm{Pb}, \mathrm{Cu}$, $\mathrm{Cr}$, and $\mathrm{Cd}$ greater than 1.5(see Table3, Table4), suggesting obvious anthropogenic inputs of these elements. Contamination of $\mathrm{Pb}$ and $\mathrm{Cd}$ are more serious than other heavy metals.

In 3 Sampling areas (FD, DS and OD), as formula [3-1] and arithmetic mean of $\mathrm{EFs}$ of $\mathrm{Cu}, \mathrm{Pb}, \mathrm{Cr}, \mathrm{Hg}$, $\mathrm{Cd}, \mathrm{Al}$ and $\mathrm{Fe}$, then calculated mean $\mathrm{EI}$ of the samples from different area, the formula EI:

$\mathrm{EI}_{\mathrm{FD}}=\sum \mathrm{EFs}_{\mathrm{FD}} /$ number of samples in the FD

$\mathrm{EI}_{\mathrm{DS}}=\sum \mathrm{EFs}_{\mathrm{DS}}$ /number of samples in the DS [3-3]

$\mathrm{EI}_{\mathrm{OD}}=\sum \mathrm{EFs}_{\mathrm{DS}} /$ number of samples in OD [3-4]

The results of $\mathrm{EI}_{\mathrm{FD}}=1.038, \mathrm{EI}_{\mathrm{DS}}=1.187$, and $\mathrm{EI}_{\mathrm{OD}}=1.116$, so we can infer the contaminated level of anthropogenic heavy metals, DS $>$ OD $>$ FD.

\subsection{Relationship between magnetic properties of materials and heavy metals contamination}

The correlation coefficient of concentrations of heavy metals and magnetic parameters were analyzed (see Table 5 ), in this study. 
Table 5 Correlation coefficient of concentrations of heavy metals and magnetic parameters

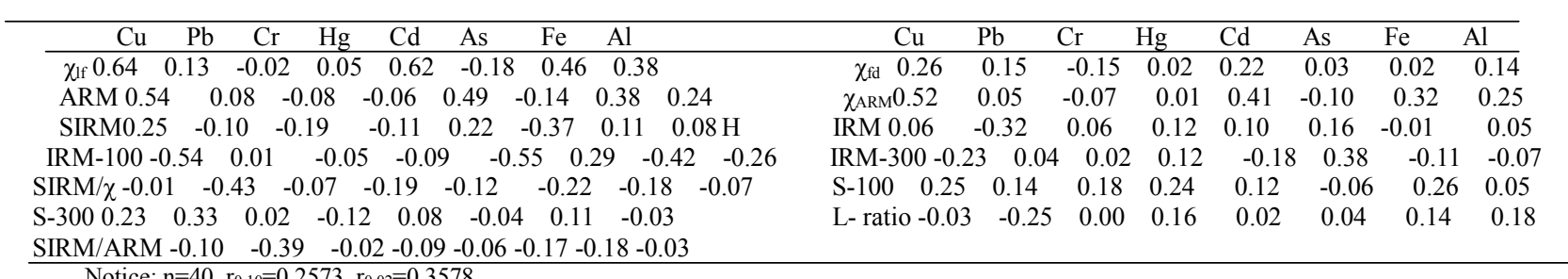

A lot of studies on the magnetic parameters were used as proxy concentration of heavy metals, in China urban, Nanjing, Lanzhou, Shanghai, Beijing, etc. Earlier study on the 1977, Beckwith et al.(1986)
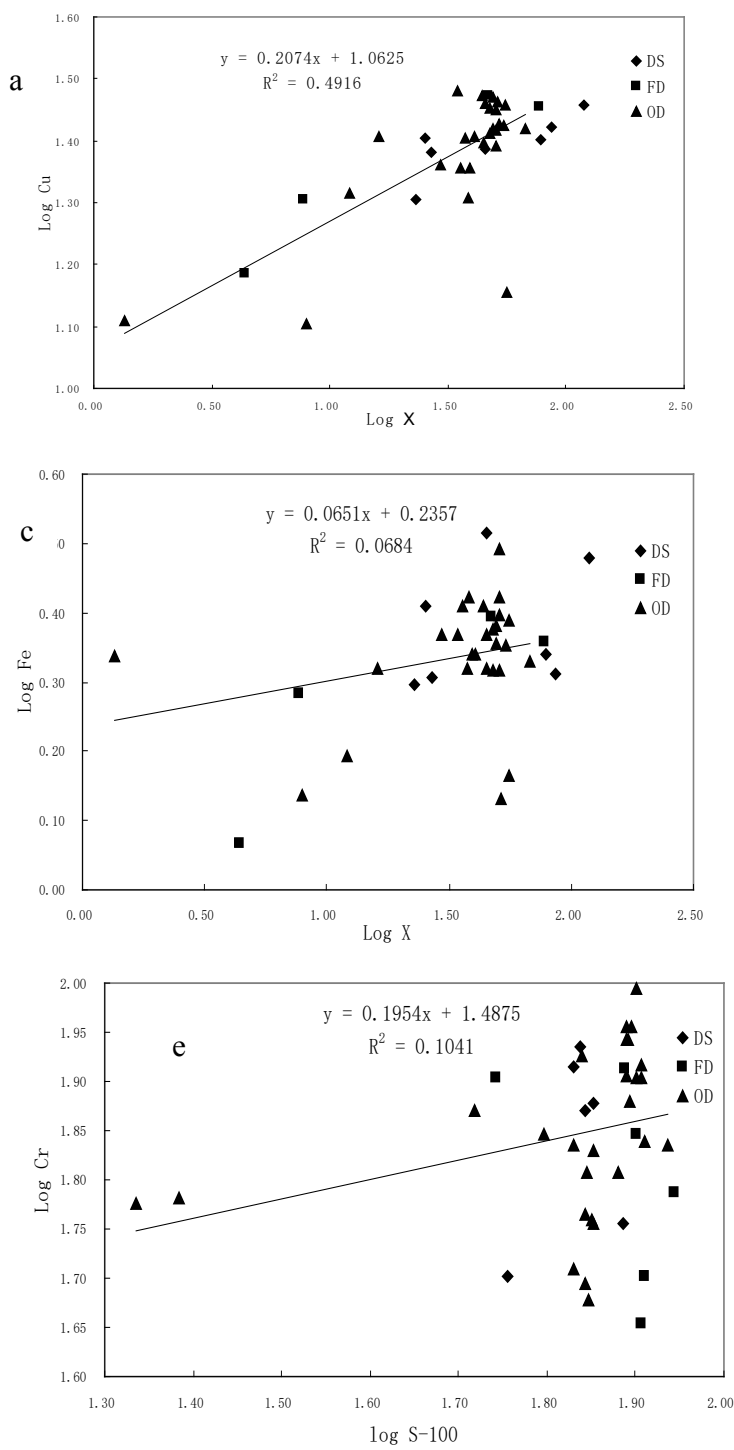

analyses of heavy metals showed positive correlations (99\%) between $\chi_{\mathrm{lf}}$ and $\mathrm{Zn}, \mathrm{Pb}$, and $\mathrm{Cu}$. (Urban soils 0-30 cm).
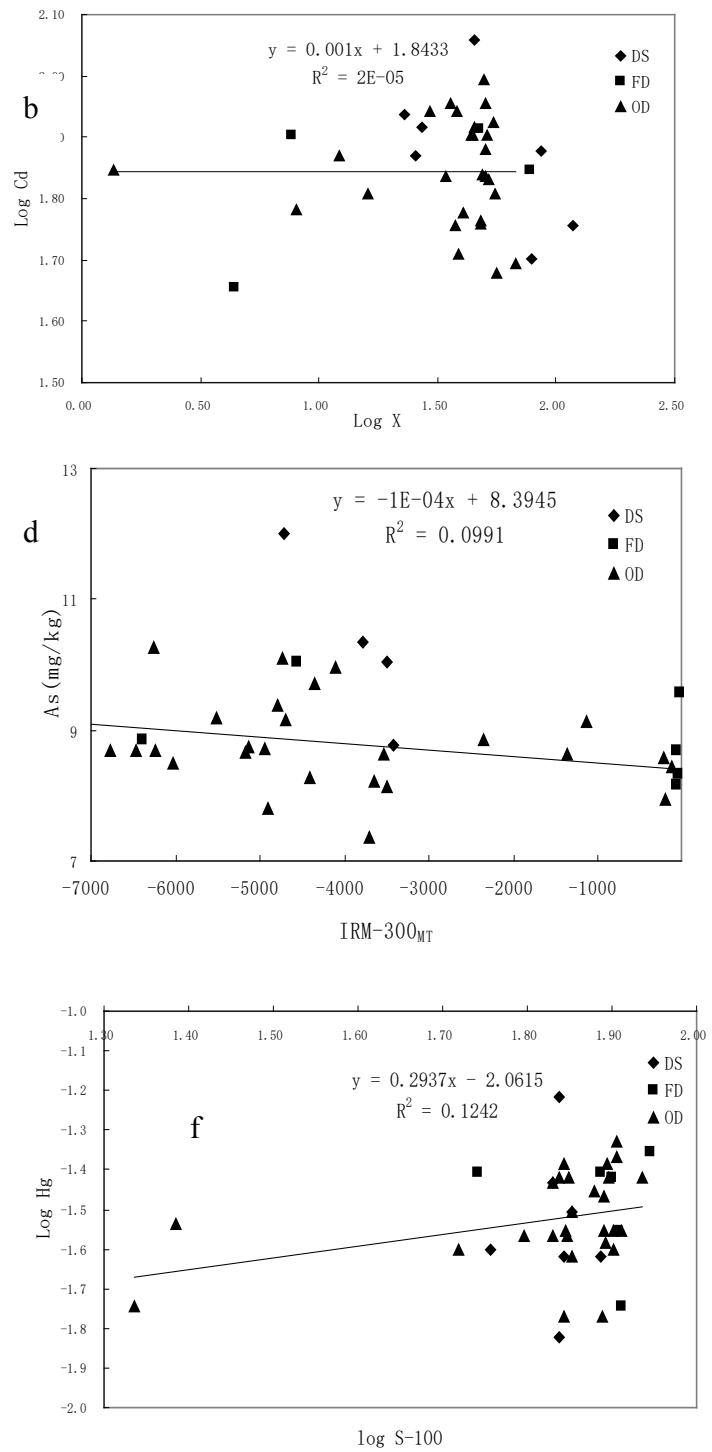


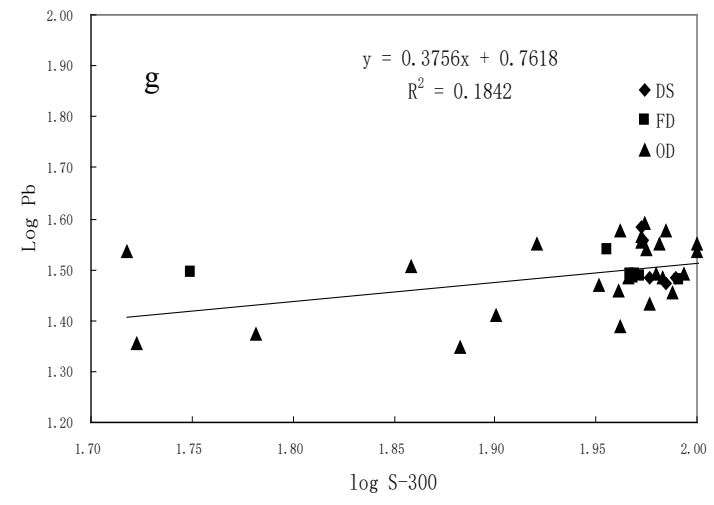

Fig.2 Relations Log-Log for all samples (n=40) between $\mathrm{Cu}(\mathrm{a}), \mathrm{Cd}(\mathrm{b}), \mathrm{Fe}(\mathrm{c}) \& \chi, \mathrm{Cr}(\mathrm{e}), \mathrm{Hg}$ (f) \& S-100, $\mathrm{Pb}(\mathrm{g}) \& \mathrm{~S}-300$, but $\mathrm{As}$ (d) \& IRM-300mT, and the correlation coefficients (R2) are calculated only for samples with OD (n=27).

The linear relation (Fig. 2) between $\log \mathrm{Cu}(\mathrm{a}), \mathrm{Cd}$ (b), Fe (c) \& $\log \chi, \log \mathrm{Cr}(\mathrm{e}), \mathrm{Hg}(\mathrm{f}) \& \log \mathrm{S}-100_{\mathrm{mT}}$, $\log \mathrm{Pb}(\mathrm{g}) \& \log \mathrm{S}-300_{\mathrm{mT}}$, and As (d) \& IRM-300 ${ }_{\mathrm{mT}}$,

\subsection{Mechanism of magnetic properties be used as proxy of heavy metals}

Great effort has been made in understanding the relationship between magnetic properties (particularly magnetic susceptibility) and the content of heavy metals, magnetite or hematite for the purposes of interpreting magnetic anomalies and rock magnetism study, and investigation of pollution.

The measured susceptibility of weakly ferromagnetic samples, in which water, carbon, calcium carbonate or silica are abundant, will be reduced by diamagnetism. According the book "Pinglu Soil", the concentration of calcite in soil profile in Antaibao is 11.3-12.5\% from $0-150 \mathrm{~cm}$.

Magnetite and hematite concentration are more relatively in oxidation than in reduction condition in sediments, because the reduction and dissolution of magnetite and hematite.

So when we want to study mechanism of magnetic properties used as proxy of heavy metals, the weak magnetic samples were measured and analyzed, we should be carefully.

The mechanism may be mainly which the origin of the magnetic fraction in the anthropogenic particulate pollution is connected with the high-temperature technological processes during production and/or processing materials which have significant $\mathrm{Fe}$ contents. suggest that these magnetic parameters can reflect the concentration variations of heavy metals.

\section{Conclusion}

Based on this study, heavy metals contamination of surface materials can be surveyed and monitored by environmental magnetism and chemical analysis, in Antaibao open pit coal mine, Shanxi Province, China. Magnetic properties can be used as proxy of heavy metals in the surface materials of AOPCM.

\section{Referrence}

1. Hao Zhi, Modern Miner. 7(1999) (in Chinese)

2. Hong Yu, Energ. Environm. Protect., 13, 2 (1995) (in Chinese)

3. S.Wang, Jin Y., \& Wang H. Environm. Sci., (1987) (in Chinese)

4. R.Thompson \& F.Oldfield, Environmental magnetism (London, George Allen \& Unwin 1986).

5. J. King, S. Banerjee, J.Marvin and O.Ozdemir, Earth Planet. Sci. Letter 59 ( 1982)

6. National Environmental Monitoring Center of China (NEMCC), Background values of elements in China soils. (Beijing, Chinese Environmental Science Publish House. 1990)

7. Wang Cong, Liu Shiliang, Qinghe Zhao, et al., Ecotoxicology and Environmental Safety,82( 2012)

8. P.R. Beckwith, J.B.Ellis, D.M.Revitt and F.Oldfield, Physics Earth Planetary Int.42 (1986) 